\title{
HIỆU QUẢ CỦA ĐIỀU TRI LÂU DÀI BẰNG HORMON TÁI TỔ HợP Ở TRẺ THIẾU HỤT HORMON TĂNG TRƯỞNG
}

\section{TÓM TẮT}

Thiếu hormon tăng trưởnq là nquyên nhân thườnq qăp qây tầm vóc thấp, đước điều tri bằnq phác đồ thay thế hormon tănq trưởng tái tổ hơp tiêm dưới da. Bênh nhân thườnq đat đước vân tốc chiều cao tối đa trong năm đâu điều tri, sau đó sẽ qiảm dân tronq nhữnq năm sau cho đến khi nqừnq điều tri. Muc tiêu: nhân xét kết quả điều tri lâu dài ở các bênh nhân sử dunq $\mathrm{GH}$ tái tổ hơp. Đối tương và phương pháp: nqhiên cứu môt loat ca bênh bao qồm 3 bênh nhân thiếu hut hormon tănq trưởng đước bắt đầu điều tri hormon tái tổ hơp thay thế ở tuổi 47 thánq và 75 thánq. Tất cả bênh nhân tai thời điểm bắt đầu điều tri đều có tầm vóc thấp (< - 4SD theo tuổi và qiới), nồnq đô IGF1 thấp hơn so với chuẩn, tuổi xươnq thấp hơn so với tuổi thưc. Phim chup MRI so não khônq phát hiên khối bất thườnq. Đối với ca bênh đầu tiên, trẻ đước làm test kích thích hormon tănq trưởnq với qlucaqon và kết quả nồnq đô $\mathrm{GH}$ đỉnh thấp 0.024 $\mathrm{nq} / \mathrm{ml}$. Phác đồ hormon thay thế đã đước điêuu tri tronq vònq 3- 5 năm. Kết quả: tốc đô tănq chiều cao đước cải thiên sau điều tri: $14-18 \mathrm{~cm}$ tronq năm đầu tiên, qiảm dân tronq các năm tiếp theo. Trẻ bắt kip tốc đô tănq trưởna bình thườnq theo WHO sau 3 năm điều tri. Kết luân: tầm vóc thấp là triêu chứnq lâm sànq chính. Điều tri hormon thay thế sớm trên trẻ bi GHD qiúp trẻ có được tốc độ tăng trưởng chiều cao bình thường.

Tư khóa: thiếu hormon tăng trưởng, lùn ở trẻ em

\section{SUMMARY}

\section{LONG-TERM OUTCOMES OF RECOMBINANT HUMAN GROWTH HORMONE THERAPY IN CHILDREN WITH GROWTH HORMONE DEFICIENCY}

Growth Hormone Deficiency (GHD) is a common cause of short stature, treated with the standard reqimen of subcutaneous synthetic qrowth hormone (GH). Patients typically achieve a maximum height velocity in the first year of treatment, which then tapers shortly after treatment is stopped. Objective: to describe long-term outcomes of patients with GHD treated with rhGH. Patients and Methods: this is case series study on three patients with qrowth hormone deficiency aqed 47 and 75 months. All patients presented with short sature $(<-4$ SD for aqe and sex); basal hormone levels showed low serum IGF1; skeletal wrist aqe was younqer than chronoloqic age; cranial MRI revealed no masses. In the first case,

*Bênh viên Nhi Trung Uơng

Chịu trách nhiệm chính: Vũ Chí Dũng

Email: dungvu@nch.org.vn

Ngày nhận bài: 17.12 .2020

Ngày phản biên khoa họ: 27.01.2021

Ngày duyệt bài: 11.2.2021

\section{Nguyễn Thị Hằng*, Vũ Chí Dũng*}

provocative qlucaqon -GH stimulation testing demonstrated a peak GH level of $0.024 \mathrm{nq} / \mathrm{mL}$.GH supplementation was started and pursued for $3-5$ vears. Results: dramatically increased heiqht velocity: $14-18 \mathrm{~cm}$ in the first year, qradually decrease in the following years. Siqnificant catch- up qrowth occurred in all of them after 3 years. Conclusion: short sature was the main clinical symtom of children on set GHD, in this case series. Early initiation of $\mathrm{GH}$ treatment in children with GHD improves their chance of achieving their normal heiqht velocity.

Keywords: growth hormone deficiency, Short stature in Children

\section{I. ĐẶT VẤN ĐỀ}

Thiếu hụt hormon tăng trưởng là nguyên nhân thường gặp gây tình trạng lùn ở trẻ em do tuyến yên không sản xuất đủ hormon tăng trưởng. Tỷ lệ mắc thiếu hụt hormon tăng trưởng dao động ở các nước khác nhau trong các báo cáo, trung bình từ $1 / 3500$ đến $1 / 4000$ trẻ [1]. Nếu không được điêuu trị, chiều cao khi trưởng thành ở trẻ nam chỉ đạt 134-146 cm, ở trẻ nữ chỉ đạt 128-134 cm [2]. Chiêu cao thấp dẫn đến khởi phát sớm các vấn đề tâm lý nghiêm trọng, tăng nguy cơ mắc các bệnh chuyển hóa khác. Hormon tăng trưởng tái tổ hợp đã được phê chuẩn và sử dụng trong lâm sàng điêu trị cho trẻ thiếu hụt hormon tăng trưởng từ 35 năm nay. Ở Việt Nam, một số nghiên cứu đã báo cáo kết quả điểu trị hormon tăng trưởng tái tổ hợp ở trẻ em thiếu hụt hormon tăng trưởng. Tuy nhiên, số lượng bệnh nhân được điều trị kéo dài còn hạn chế. Nghiên cứu này sẽ báo cáo loạt ca bệnh đã được chẩn đoán thiếu hụt hormon tăng trưởng, quá trình điều trị dài hạn bằng hormon thay thế mang lại hiệu quả cao.

\section{BÁO CÁO CA BỆnH}

Ca bệnh 1. Trẻ nữ, con lần 2, đẻ thường, đủ tháng, ngôi đầu, cân nặng lúc sinh 3,0 kg, không có tiên sử ngạt, suy hô hấp lúc đẻ. Tiên sử gia đình, bố cao $169 \mathrm{~cm}$, mẹ cao $166 \mathrm{~cm}$ và anh trai 14 tuổi cao $165 \mathrm{~cm}$. Tại thời điểm thăm khám: trẻ 3 tuổi 11 tháng; chiêu cao $85 \mathrm{~cm}$ (tương đương 4.01 SD theo WHO), cân nặng 12,3 kg (tương đương $-2.16 \mathrm{SD}$ theo WHO); trẻ phát triển tâm thân vận động phù hợp so với lứa tuổi, mặt bâu và cằm nhỏ nhưng không có bất thường hình thái khác. Các xét nghiệm tại thời điểm ban đâu: TSH 2,39 mIU/l; T3 1,75 nmol/l; T4 56,4 nmol/l; Ure 6,35 mmol/l; Creatinine 47,12 $\mu \mathrm{mol} / \mathrm{l} ; \mathrm{GOT} / \mathrm{GPT}$ : 
$39 / 16 \mathrm{mmol} / \mathrm{l}$; calci toàn phần $2,34 \mathrm{mmol} / \mathrm{l} ; \mathrm{Hb}$ $104 \mathrm{~g} / \mathrm{l} ;$ IGF1 < $25 \mathrm{ng} / \mathrm{ml}$; nghiệm pháp kích thích $\mathrm{GH}$ với glucagon có nồng độ $\mathrm{GH}$ đỉnh 0,024 $\mathrm{ng} / \mathrm{ml}$ xquang tuổi xương tương đương trẻ 20 tháng tuổi; MRI sọ não không phát hiện bất thường; nhiễm sắc thể $46, X X$. Trẻ được điều trị liệu pháp hormon thay thế với liều 0,025 $\mathrm{mg} / \mathrm{kg} / \mathrm{ngày}-0,03 \mathrm{mg} / \mathrm{kg} / \mathrm{ngày}$, tiêm dưới da hằng ngày. Kết quả cho thấy sau năm thứ nhất, trẻ tăng được $18 \mathrm{~cm}$, năm thứ 2 và năm thứ $3:$ mỗi năm trẻ tăng được $5 \mathrm{~cm}$. Chiêu cao của trẻ cải thiện từ chậm $(-4,01 \mathrm{SD})$ trước điều trị còn chậm $(-1,52 \mathrm{SD})$ sau 3 năm theo tổ chức y tế thế giới (TCYTTG), nếu so với hằng số sinh học người Việt Nam: chiêu cao của trẻ cải thiện từ $(-2,85 \mathrm{SD})$ lên $(0,34 \mathrm{SD})$ sau 3 năm. Cân nặng của trẻ từ $(-2,16$ SD) trước điều trị lên $(-0,25 \mathrm{SD})$ sau 3 năm điều trị theo TCYTTG. Tuổi xương đã bắt kịp tuổi thực sau 3 năm điêu trị. Không có tác dụng phụ nào được ghi nhận.

Ca bệnh 2. Trẻ trai, con lần 2, đẻ mổ vì sẹo mổ cũ, đủ tháng, cân nặng lúc sinh $2,9 \mathrm{~kg}$, không có tiền sử ngat, suy hô hấp lúc đẻ. Bố cao $167 \mathrm{~cm}$, me cao $158 \mathrm{~cm}$ và anh trai 6 tuổi cao $112 \mathrm{~cm}$, trẻ được mẹ cho khám vì lùn hơn so với các bạn trong lớp. Tại thời điểm thăm khám trẻ 3 tuổi 11 tháng, chiều cao $85 \mathrm{~cm}$ tương đương (4,27 SD) theo TCYTTG, cân nặng $13 \mathrm{~kg}$ tương đương $(-2,01 \mathrm{SD})$ theo TCYTTG, trẻ phát triển tâm thần vận động phù hợp so với lứa tuổi, không vàng da, không táo bón, không có bất thường hình thể khác, chiều dài dương vât 2,5 $\mathrm{cm}$, thể tích tinh hoàn mỗi bên $1 \mathrm{ml}$. Các xét nghiệm tại thời điểm ban đầu: TSH 0,79 mIU/l; $\mathrm{T} 3$ = 3,11 nmol/l; T4 $117 \mathrm{nmol} / \mathrm{l} ;$ Ure $5 \mathrm{mmol} / \mathrm{l}$; Creatinine $38 \mu \mathrm{mol} / \mathrm{l} ; \mathrm{GOT} / \mathrm{GPT} 44 / 16 \mathrm{mmol} / \mathrm{l}$; calci toàn phần 2,51 mmol/l; Hb $144 \mathrm{~g} / \mathrm{l} ;$ IGF1 $42 \mathrm{ng} / \mathrm{ml}$; nồng độ $\mathrm{GH}$ tînh/động: 2,16/2,5 $\mathrm{ng} / \mathrm{ml}$; xquang tuổi xương tương đương trẻ 3 tuổi; MRI so não có tổn thương chất trắng cạnh sừng chẩm não thất 2 bên, không có khối bất thường. Trẻ được điều trị liệu pháp hormon thay thế với liêu $0,03 \mathrm{mg} / \mathrm{kg} / \mathrm{ngày}-0,035, \mathrm{mg} / \mathrm{kg} / \mathrm{ngày}$, tiêm dưới da hằng ngày. Kết quả cho thấy sau năm thứ nhất, trẻ tăng được 14,5 cm, năm thứ 2 và năm thứ 3: mỗi năm trẻ tăng lần lượt $5,5 \mathrm{~cm}$ và $6,5 \mathrm{~cm}$. Chiều cao của trẻ cải thiện từ $(-4.27$ SD) trước điều trị lên (-1,94 SD) sau 3 năm theo
TCYTTG, nếu so với hằng số sinh học người Việt Nam: chiều cao của trẻ cải thiện từ (- 2,99 SD) lên $(0,01 \mathrm{SD})$ sau 3 năm. Cân nặng của trẻ từ (2,01 SD) trước điều trị lên $(-0,86 \mathrm{SD})$ sau 3 năm điêu trị theo TCYTTG. Trẻ không gặp tác dụng phụ nào.

Ca bệnh 3. Trẻ nam con lần 4, đẻ thường, đủ tháng, ngôi ngược, cân nặng lúc sinh $3,3 \mathrm{~kg}$, không có tiền sử ngạt, suy hô hấp lúc đẻ. Gia đình, bố cao $160 \mathrm{~cm}$, mee cao $157 \mathrm{~cm}$ và ba chị gái không thấp hơn các bạn cùng tuổi, trẻ được me cho khám vì lùn hơn các ban trong lớp. Tại thời điểm thăm khám trẻ 6 tuổi 4 tháng, chiều cao $94 \mathrm{~cm}$ tương đương $(-4,74 \mathrm{SD})$ theo TCYTTG, cân nặng 14,5 kg tương đương $(-3,53$ SD) theo TCYTiG, tré phát triển tâm thần vận động phù hợp so với lứa tuổi, học lực khá, có bộ mặt suy yên: mặt bầu, trán dô và mũi gãy, không kèm theo bất thường hình thể khác, không vàng da, không táo bón, chiều dài dương vât $3 \mathrm{~cm}$, thể tích tinh hoàn mối bên 1-2 ml. Các xét nghiệm tại thời điểm ban đầu: TSH 0,9 $\mathrm{mIU} / \mathrm{l} ; \mathrm{T} 3=1,37 \mathrm{nmol} / \mathrm{l} ; \mathrm{T} 451,1 \mathrm{nmol} / \mathrm{l} ;$ Ure $3,05 \mathrm{mmol} / \mathrm{l} ;$ Creatinine 48,1 umol/l; GOT/GPT $35 / 11 \mathrm{mmol} / \mathrm{l}$; calci toàn phần $2,46 \mathrm{mmol} / \mathrm{l} ; \mathrm{Hb}$ 115 g/l; IGF1 128 ng/ml; nồng độ GH tĩnh/động $0,525 / 2,56 \mathrm{ng} / \mathrm{ml}$, xquang tuổi xương tương đương trẻ 2 tuổi, MRI sọ não không phát hiện tổn thương. Trẻ được điều trị liêu pháp hormon thay thế với liêu $0.025 \mathrm{mg} / \mathrm{kg} / \mathrm{ngày}-0.03$ $\mathrm{mg} / \mathrm{kg} / \mathrm{ngày}$, tiêm dưới da hằng ngày. Kết quả cho thây sau năm thứ nhất, trẻ tăng được 14 $\mathrm{cm}$, năm thứ 2 trẻ tăng $10 \mathrm{~cm}$, năm thứ 3 trẻ tăng $6,5 \mathrm{~cm}$, năm thứ 4 và năm thứ 5 trẻ tăng lần lượt $7,5 \mathrm{~cm}$ và $6,5 \mathrm{~cm}$. Chiều cao của trẻ cải thiên từ $(-4,74$ SD) trước điều trị lên $(-1,76$ SD) sau 2 năm điều trị và sau 5 năm chiều cao trẻ đạt $(-0,81 \mathrm{SD})$ theo TCYTTG, nếu so với hằng số sinh học người Việt Nam: chiều cao của trẻ cải thiên từ $(-3,3 \mathrm{SD})$ lên $(-0,57 \mathrm{SD})$ sau năm đầu tiền và đat $(1,56 \mathrm{SD})$ sau 5 năm điều trị. Cân nặng của trẻ từ $(-3,53 \mathrm{SD})$ trước điều trị lên $(-1,51 \mathrm{SD})$ sau 1 năm điều trị và đat $(0,05 \mathrm{SD})$ sau 5 năm điều trị theo TCYTTG. Tuổi xương của trẻ đã tương đương so với tuổi thực sau 5 năm điều trị. Không có tác dụng phụ nào được ghi nhận trên trẻ.

Bảng 1. Đặc điểm lâm sàng và kết quả điều trị

\begin{tabular}{|c|c|c|c|c|}
\hline \multicolumn{2}{|c|}{ Yếu tộnh nhân } & Ca bệnh 1 & Ca bệnh 2 & Ca bệnh 3 \\
\hline \multirow{2}{*}{} & Giới & Nữ & Nam & Nam \\
\cline { 2 - 5 } & Tuối bắt đầu điều trị (tháng) & 47 & 47 & 75 \\
\hline
\end{tabular}


TAP CHÍ Y HOC VIẸT NAM TÂP 499 - THÁNG 2 - SÓ $1 \& 2$ - 2021

\begin{tabular}{|c|c|c|c|c|}
\hline \multirow{3}{*}{$\begin{array}{l}\text { Trước } \\
\text { điêu trị }\end{array}$} & Chiêu cao T0 theo TCYTTG (SD) & $-4,01$ & $-4,27$ & $-4,74$ \\
\hline & Cân nặng T0 theo TCYTTG (SD) & $-2,16$ & $-2,01$ & $-3,53$ \\
\hline & Tuối xương T0 (tháng) & 20 & 36 & 24 \\
\hline \multirow{6}{*}{$\begin{array}{c}\text { Sau } \\
\text { điều trị }\end{array}$} & Thời gian điều trị ( năm) & 3 & 3 & 5 \\
\hline & Liều điều trị (mg/kg/ngày) & $0,025-0,03$ & $0,03-0,035$ & $0,025-0,03$ \\
\hline & Chiều cao theo TCYTTG (SD) & $-1,52$ & $-1,94$ & $-0,81$ \\
\hline & Cân nặng theo TCYTTG (SD) & $-0,25$ & $-0,86$ & 0,05 \\
\hline & Chênh lệch tuối thực và tuối xương (năm) & 0 & 2 & 0 \\
\hline & Tác dụng không mong muốn & Không & Không & Không \\
\hline \multirow{5}{*}{$\begin{array}{l}\text { Tăng } \\
\text { chiều } \\
\text { cao } \\
(\mathrm{cm})\end{array}$} & Năm thứ nhất & 18 & 14,5 & 14 \\
\hline & Năm thứ hai & 5 & 5,5 & 10 \\
\hline & Năm thứ ba & 5 & 6,5 & 6,5 \\
\hline & Năm thứ tư & & & 7,5 \\
\hline & Năm thứ năm & & & 6,5 \\
\hline
\end{tabular}

SD: Standard Deviation: Độ lệch chuẩn; T0: thời điểm bắt đầu điều trị;

Nhận xét: Điều trị thay thế hormon tái tổ hợp có tác dụng cải thiện chiều cao, cân nặng và tuổi xương của bệnh nhân. Tốc độ tăng trưởng chiều cao lớn nhất trong năm đầu và giảm dân trong những năm sau đó. Sau 3 năm điêu trị, bệnh nhân đã bắt kịp tốc độ tăng trưởng so với quần thể bình thường theo TCYTTG.

\section{BÀN LUÂ̂N}

Thiếu hụt hormon tăng trưởng là bệnh lý thiếu hụt hormon $\mathrm{GH}$ do tuyến yên bài tiết. Thiếu hụt này có thể xảy ra đơn thuần hoặc phối hợp các hormon khác của tuyến yên. Lâm sàng của bệnh đa dạng và phụ thuộc từng lứa tuổi: đối với lứa tuổi sơ sinh, các biểu hiện của bệnh có thể là hạ glucose máu, hạ nhiệt độ, dương vật nhỏ. Trong khi đó, biểu hiện chính của bệnh ở tuổi lớn hơn là lùn và bất thường về hình thể. Tiêu chuẩn chẩn đoán bệnh trong thực hành lâm sàng theo hướng dẫn của Hội các nhà nội tiết lâm sàng Hoa Kỳ năm 2003 [3] và Hội nội tiết nhi khoa Hoa Kỳ [4]. Các tiêu chuẩn bao gồm: i/ trẻ có chiều cao $(<-2 \mathrm{SD})$ so với quần thể cùng tuổi, cùng giới (đã loại trừ những nguyên nhân gây chậm tăng trưởng khác: suy giáp trạng bẩm sinh, bệnh mạn tính, hội chứng Turner); ii/ chiêu cao dự báo dưới $(-1,5 \mathrm{~S} D$ so với chiêuu cao trung binh của bố mẹ; iii/ chiều cao dưới ( $-2 \mathrm{SD}$ ) và tốc độ tăng trưởng chiều cao dưới (-1 SD) trong vòng 1 năm hoặc độ lệch chuẩn chiều cao giảm trên $(0,5 \mathrm{SD})$ trong vòng 1 năm ở trẻ trên 2 tuổi; iv/ trong trường hợp không có tầm vóc thấp, tốc độ tăng trưởng chiêu cao dưới (- $2 \mathrm{SD}$ ) trong vòng 1 năm hoặc dưới (-1,5 SD) trong vòng 2 năm; v/ dấu hiệu lâm sàng của tổn thương nội sọ, thiếu hụt hormon khác của tuyến yên: hạ glucose máu, vàng da kéo dài, dương vật nhỏ ở trẻ sơ sinh; vi/ nghiệm pháp kích thích $\mathrm{GH}$ với nồng độ $\mathrm{GH}$ đình trong huyết tương $<10 \mathrm{ng} / \mathrm{ml}$ (nghiệm pháp kích thích với Clonidine, Glucagon hoặc Insulin); vii/ nồng độ IGF1 và/hoặc IGFBP3 dưới (-2 SD) so với quần thể bình thường cùng tuổi và giới; viii/ Xquang tuổi xương: chậm hơn so với tuổi thực.

Năm 1985, cơ quan quản lý thực phẩm và dược phẩm Hoa Kỳ đã chấp thuận GH tái tổ hợp của Genentech được sử dụng trong điều trị bệnh nhân thiếu hụt hormon tăng trưởng ở trẻ em [5]. Từ đó đến nay, liệu pháp thay thế hormon tăng trưởng tái tổ hợp đã được sử dụng trên hàng chục nghìn bệnh nhân thiếu hụt hormon tăng trưởng và chứng minh được tính an toàn và hiệu quả [6].

Trong nghiên cứu này, cả 3 bệnh nhân lùn được gia đình đưa đến khám trước 7 tuổi, được chẩn đoán thiếu hụt hormon tăng trưởng và được điêu trị bằng liệu pháp hormon tái tổ hợp thay thế với liều thấp: bắt đầu từ liều 0,025 $\mathrm{mg} / \mathrm{kg} / \mathrm{ngày}-0,03 \mathrm{mg} / \mathrm{kg} / \mathrm{ngày}$, tiêm dưới da hằng ngày. Cả 3 bệnh nhân đều cải thiện tốc độ tăng trưởng chiều cao trong những năm sau điêu trị, đặc biệt trong năm đầu tốc độ tăng trưởng chiều cao đạt $14-18 \mathrm{~cm} /$ năm. Tốc độ tăng trưởng chiều cao có xu hướng giảm dần trong những năm tiếp theo. Ngoài ra, điều trị hormon tăng trưởng cải thiện cân nặng của bệnh nhân, giúp tuổi xương bắt kịp tuổi thực và thuốc an toàn, không ghi nhận tác dụng không mong muốn nào.

Trong các nghiên cứu trên thế giới, tốc độ tăng trưởng tăng từ $2-4 \mathrm{~cm} /$ năm trước điều trị lên $10-12 \mathrm{~cm} / \mathrm{năm}$ đầu sau điều trị, $7-9 \mathrm{~cm} / \mathrm{năm}$ thứ hai và năm thứ ba sau điều trị [7]. Tốc độ tăng trưởng chiều cao cải thiện từ $(-3,9 \mathrm{SD})$ lên $(-2,6 \mathrm{SD})$ theo TCYTTG sau 6 năm điêu trị [8]. Các nghiên cứu cũng chỉ ra, tốc độ tăng trưởng 
chiều cao phụ thuộc nhiều yếu tố như: mức độ nặng (nồng độ GH đỉnh thời điểm chẩn đoán), tuổi bắt đầu điều trị, liều điều trị hay chiều cao di truyền của bố mẹ.

Trong báo cáo của chúng tôi, tại thời điểm chẩn đoán, chiều cao của 3 bệnh nhân đều $(<-4$ SD) theo TCYTTG, sau 3 năm điêuu trị, chiều cao 3 bệnh nhân đã bắt kịp được tốc độ tăng trưởng bình thường. Kết quả này phù hợp các nghiên cứu trên thế giới, với giả thuyết tốc độ tăng trưởng chiêu cao trong những năm sau thấp hơn so với năm đầu do sư xuất hiên của kháng thể chống lại GH tái tổ hợp. Vì vâyy, chúng tôi tin rằng báo cáo này có ý nghĩa trong việc bổ sung vào y văn là việc sử dụng hormon tăng trưởng tái tổ hợp là an toàn và hiệu quả.

\section{KẾT LUÂN}

Cả 3 bệnh nhân bị thiếu hụt hormon tăng trưởng được chẩn đoán sớm, chiêu cao tại thời điểm chẩn đoán chậm nặng và được điều trị thay thế bằng $\mathrm{GH}$ tái tổ hợp tiêm dưới da hằng ngày. Báo cáo này chỉ ra hiệu quả và an toàn của thuốc, tốc độ tăng trưởng chiêu cao lớn nhất trong năm đầu $14-18 \mathrm{~cm} /$ năm và giảm dần trong các năm sau; không có tác dụng không mong muốn nào được ghi nhận trên bệnh nhân. Tuy nhiên, cần có các nghiên cứu lớn hơn tại Việt Nam để khẳng định tính hiệu quả và an toàn của thuốc.

\section{TÀI LIẸU THAM KHẢO}

1. Dattani M., and Preece M. (2004). Growth hormone deficiency and related disorders: insights into causation, diagnosis, and treatment. Lancet Lond Engl, 363(9425), 1977-1987.

2. Takeda A., Cooper K., Bird A, et al. (2010). Recombinant human growth hormone for the treatment of growth disorders in children: a systematic review and economic evaluation. Health Technol Assess Winch Engl, 14(42), 1-209.

3. Gharib H., Cook D.M., Saenger P.H, et al. (2003). American Association of Clinical Endocrinologists medical guidelines for clinical practice for growth hormone use in adults and children--2003 update. Endocr Pract Off J Am Coll Endocrinol Am Assoc Clin Endocrinol, 9(1), 64-76.

4. Grimberg A., DiVall S.A., Polychronakos $C_{\text {, }}$ et al . (2016). Guidelines for Growth Hormone and Insulin-Like Growth Factor-I Treatment in Children and Adolescents: Growth Hormone Deficiency, Idiopathic Short Stature, and Primary Insulin-Like Growth Factor-I Deficiency. Horm Res Paediatr, 86(6), 361-397.

5. Ayyar V.S. (2011). History of growth hormone therapy. Indian J Endocrinol Metab, 15(3), 162165.

6. Hou L., Luo X., Du M, et al. (2009). [Efficacy and safety of recombinant human growth hormone solution in children with growth hormone deficiency in China: a multicenter trial]. Zhonghua Er Ke Za Zhi Chin J Pediatr, 47(1), 48-52.

7. Korpal-Szczyrska M., Dorant B., Kamińska H, et al. (2006). Evaluation of final height in patients with pituitary growth hormone deficiency who were treated with growth hormone replacement. Endokrynol Diabetol Chor Przemiany Materii Wieku Rozw Organ Pol Tow Endokrynol Dzieciecych, 12(1), 31-34.

8. Salah N., Abd El Dayem S.M., El Mogy F, et al. (2013). Egyptian growth hormone deficient patients: demographic, auxological characterization and response to growth hormone therapy. J Pediatr Endocrinol Metab JPEM, 26(34), 257-269.

\section{ĐÁNH GIÁ NGUY CƠ TỬ VONG Ở BỆNH NHÂN NHIỄM KHUẨN NĂNG Có TỔN THƯƠ'NG THẬN CẤP}

\section{TÓM TĂT}

Mục tiêu: Đánh giá một số yếu tố nguy cơ tới tổn thương thận và tử vong ở bệnh nhân nhiễm khuẩn năng. Đối tướng và phương pháp nghiên cứu: Bệnh nhân nhiểm khuẩn nặng điêu trị tại khoa Hồi sức tích cức bênh viện Bach Mai theo phướng pháp mô tả tiến cứu. Kết quả: Nhiễm khuẩn nặng làm tăng nquy cơ tổn thương thận 2,1 lần, $p<0,05$; Bệnh nhân nhiềm

*Trung tâm Chống độc -Bênh viên Bach Mai.

Chịu trách nhiệm chính: Đặng Thị Xuân

Email: xuandangthi17@gmail.com

Ngày nhận bài: 18.12 .2020

Ngày phản biên khoa hoc: 22.01.2021

Ngày duyệt bài: 5.2 .2021
Đặng Thị Xuân*

khuẩn nặng có tổn thương thân cấp tử vong rất cao $61,6 \%$, nguy cơ tử vong gấp 4,7 lần so với bệnh nhân không tổn thương thận (OR 4,7; $p<0,001)$. Những bệnh nhân nặng phải lọc máu tỉ lệ tử vong lên tới $75 \%$, nguy cớ tữ vong gấp 21 lần so với những bệnh nhân không phải loc máu (OR 21; $\mathrm{p}<0,001)$. Nhóm bệnh nhân suy thận muộn sau khi vào viện tử vong cao nhất $(80 \%, p<0,01)$, thường trong tình trang suy đa tạng; nguy cơ tử vong gấp 8 lần nhóm mức độ nhẹ khi vào viện, (OR 8,$0 ; p<0,001)$. Kết luân: Nhiễm khuẩn nặng làm tăng nguy cơ tổn thương thận cấp. Nhiễm khuẩn năng có tổn thương thân tăng nguy cơ tử vong, đặc biệt nhóm nă̆ng phải lọc máu vàtổn thương thân muộn sau vào hồi sức.

Tư khóa: Tổn thương thận cấp, nhiễm khuẩn nặng, RIFLE. 